\title{
Surface Processing to Improve the Fatigue Resistance of Advanced Bar Steels for Automotive Applications
}

\author{
David K. Matlock*, Khaled A. Alogab, Mark D. Richards, John G. Speer \\ Advanced Steel Processing and Products Research Center, \\ Department of Metallurgical and Materials Engineering, \\ Colorado School of Mines, Golden, Colorado - USA
}

Received: July 19, 2004; Revised: October 14, 2005

\begin{abstract}
With the development of new steels and processing techniques, there have been corresponding advances in the fatigue performance of automotive components. These advances have led to increased component life and smaller power transfer systems. New processing approaches to enhance the fatigue performance of steels are reviewed with an emphasis on carburizing and deep rolling. Selected examples are presented to illustrate the importance of the base steel properties on the final performance of surface modified materials. Results on carburized gear steels illustrate the dependence of the fatigue behavior on carburizing process control (gas and vacuum carburizing), alloy additions and microstructure. The importance of retained austenite content, case and core grain size as controlled by processing and microalloy additions, extent of intergranular oxidation, and the residual stress profile on fatigue performance is also illustrated. Specific recent results on the use of microalloying elements (e.g. Nb) and process history control to limit austenite grain growth at the higher carburizing temperatures associated with vacuum carburizing are highlighted. For crankshaft applications, deep rolling is highlighted, a process to mechanically work fillet surfaces to improve fatigue resistance. The influence of the deformation behavior of the substrate, as characterized by standard tensile and compression tests, on the ability to create desired surface properties and residual stress profiles will be illustrated with data on several new steels of current and future interest for crankshaft applications.
\end{abstract}

Keywords: carburized steels, deep rolling, niobium additions

\section{Introduction}

With improvements in steel making, there have been significant advances in the development of bar steels for fatigue-sensitive automotive applications, such as gears and shafts. Automotive design requirements that demand smaller and lighter components without sacrificing torque or force capacity have led to the need for components with significantly improved fatigue performance. To satisfy these needs, material/processing combinations that concentrate on surface microstructure have been developed.

Improvements in fatigue performance in components are derived primarily by decreasing the surface cyclic tensile stress or by increasing the surface yield stress, thereby increasing the resistance to fatigue crack nucleation. To achieve these goals, common surface modification processes, which often simultaneously increase the surface yield stress and introduce a residual compressive stress to decrease the surface cyclic tensile stress, are based on heat treating (e.g. carburizing, carbonitriding, laser hardening, and induction hardening), non-uniform plastic deformation (e.g. peening and deep rolling), or selected surface alloy modification (e.g. ion implantation and chemical or physical vapor deposition). To realize the maximum improvement in fatigue performance these surface modification techniques must be carefully controlled and matched with the particular alloy of interest to ensure that undesirable features (e.g. microcracks, incorrect microstructure, etc) are not introduced during manufacture.

In this paper the importance of understanding the interactions between steel alloy composition and microstructure, as controlled by processing, with selected surface modification techniques is presented. This paper is based on the results of multiple investigations in the authors' laboratories and is presented in two parts. The first part concentrates on carburized steel testing results obtained on a special laboratory sample designed to simulate root-bending fatigue ${ }^{1-5}$, of gear teeth and the second part summarizes recent results on deep rolled laboratory samples designed to simulate crankshaft fillets.

\section{Carburized Steel}

\subsection{Alloying concepts}

Steels with optimal fatigue resistance possess several desirable alloying and processing characteristics. The case should consist of a high-carbon tempered martensite and retained austenite without the presence of non-martensite transformation (NMT) products. Alloying elements that increase hardenability, e.g. Ni, $\mathrm{Cr}, \mathrm{Mn}$, and $\mathrm{Mo}$, suppress the formation of non-martensitic transformation products upon quenching. In addition, $\mathrm{Ni}$ is often added to improve martensite toughness. Some automotive carburizing steel grades are summarized in Table 1. Large carbides, oxides, and other second-phase particles are to be avoided. These structures may either combine with other features that initiate fatigue cracks, or in the absence of such features, serve as the sole source of fatigue crack initiation. Consequently, careful control of strong-oxide-forming elements (e.g. Cr, $\mathrm{Si}, \mathrm{Mn}$ ), in addition to control of $\mathrm{S}$ and $\mathrm{P}$, is required in conventional gas-carburizing furnaces. As will be shown below, austenite grain size refinement is also critical ${ }^{6}$. With the increased use of vacuum or plasma carburizing furnaces, it may be more straightforward and cost effective to 
utilize high-hardenability, oxide-forming elements (e.g. Si) to control specific microstructural features to enhance fatigue resistance ${ }^{7,8}$.

\subsection{Bending fatigue failure mechanisms in carburized steels}

Carburized steels, directly quenched after carburizing, develop case microstructures consisting of plate martensite and retained austenite, and may be susceptible to intergranular cracking ${ }^{3,9}$. In bending fatigue, cracks initiate intergranularly and propagate as stable transgranular cracks, which eventually reach critical crack lengths and propagate as unstable intergranular $\mathrm{cracks}^{3}$. Figure 1 shows a typical fracture progression of bending fatigue in carburized 4820 steel. Figure 1a shows an overview of the stable transgranular crack with a schematic drawing as an insert that illustrates the specific fracture regions, and at higher magnification, Figure 1b shows intergranular initiation at the surface, Figure 1c shows the interface of the transgranular crack and the intergranular unstable crack, and
Figure 1d shows the intergranular decohesion associated with overload propagation.

In direct-quenched gear steels the fatigue life has been shown to correlate with the susceptibility of fatigue crack nucleation by intergranular fracture ${ }^{1}$ which may result from two primary reasons: (a) the presence of intergranular oxides (IGO) produced during conventional gas carburizing ${ }^{2-6}$; or (b) the susceptibility of the austenite grain boundaries to quench embrittlement, i.e. intergranular fracture due to the presence of cementite formed on austenite grain boundaries during heat treating ${ }^{7,10}$.

In the absence of shot peening or other surface deformation processes, one of the primary metallurgical approaches available to control fatigue performance of advanced automotive bar steels, is to carefully control the alloy content and processing to minimize intergranular fatigue crack nucleation. For example, moderate to good endurance limits of 1000-1300 MPa have been observed ${ }^{1}$ when the initial fatigue

Table 1. Nominal compositions of automotive carburizing steels; S and P less than 0.025 (wt. pct).

\begin{tabular}{ccccccc}
\hline \multicolumn{1}{c}{ Steel } & $\mathrm{C}$ & $\mathrm{Mn}$ & $\mathrm{Si}$ & $\mathrm{Cr}$ & $\mathrm{Ni}$ & $\mathrm{Mo}$ \\
\hline SAE 9310 & $0.08-0.13$ & $0.45-0.65$ & $0.15-0.35$ & $1.00-1.40$ & $3.00-3.50$ & $0.08-0.15$ \\
SAE 4320 & $0.17-0.22$ & $0.45-0.65$ & $0.15-0.35$ & $0.40-0.60$ & $1.65-2.00$ & $0.20-0.30$ \\
SAE 8620 & $0.18-0.23$ & $0.70-0.90$ & $0.15-0.35$ & $0.40-0.60$ & $0.40-0.70$ & $0.15-0.25$ \\
SAE 4820 & $0.18-0.23$ & $0.50-0.70$ & $0.15-0.35$ & - & $3.25-3.75$ & $0.20-0.30$ \\
SAE 4118 & $0.18-0.23$ & $0.70-0.90$ & $0.20-0.35$ & $0.40-0.60$ & - & $0.08-0.15$ \\
SCM420 & $0.18-0.23$ & $0.60-0.85$ & $0.15-0.35$ & $0.90-1.20$ & $<0.25$ & $0.15-0.30$ \\
20MnCr5 & $0.17-0.22$ & $1.10-1.40$ & $0.15-0.40$ & $1.00-1.30$ & - & - \\
\hline
\end{tabular}

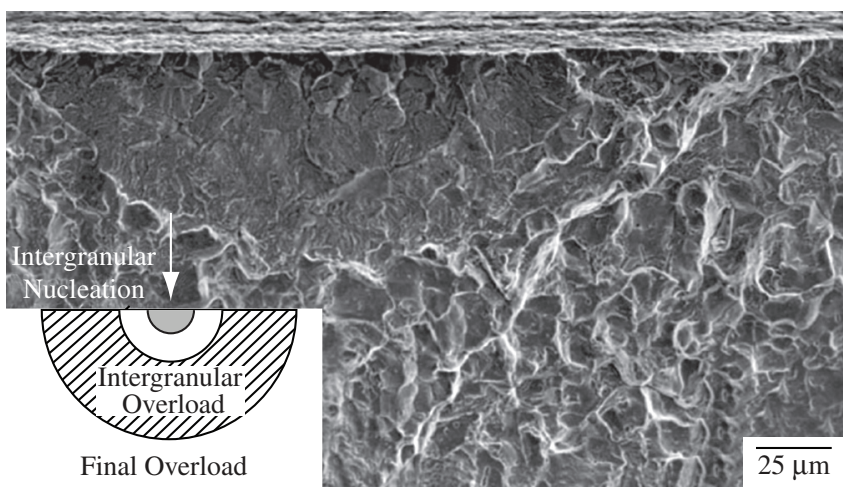

(a)

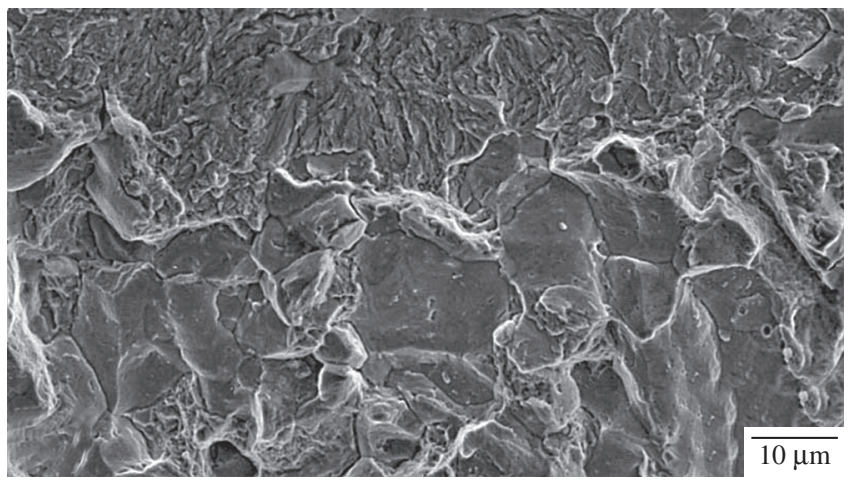

(c)

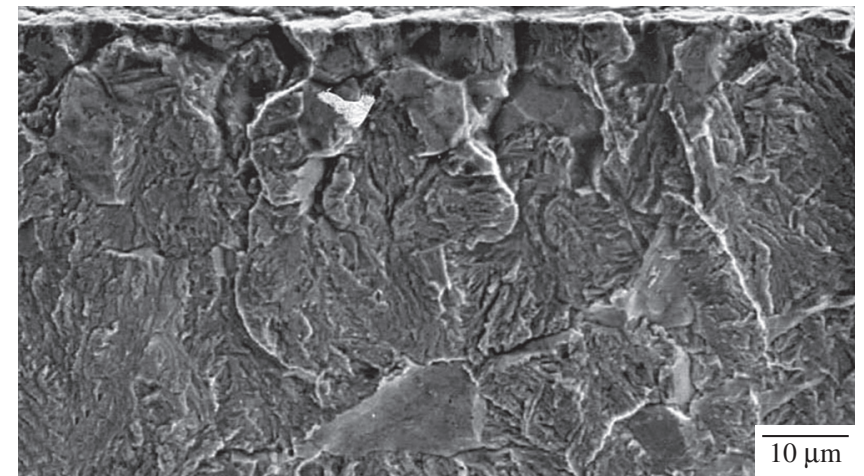

(b)

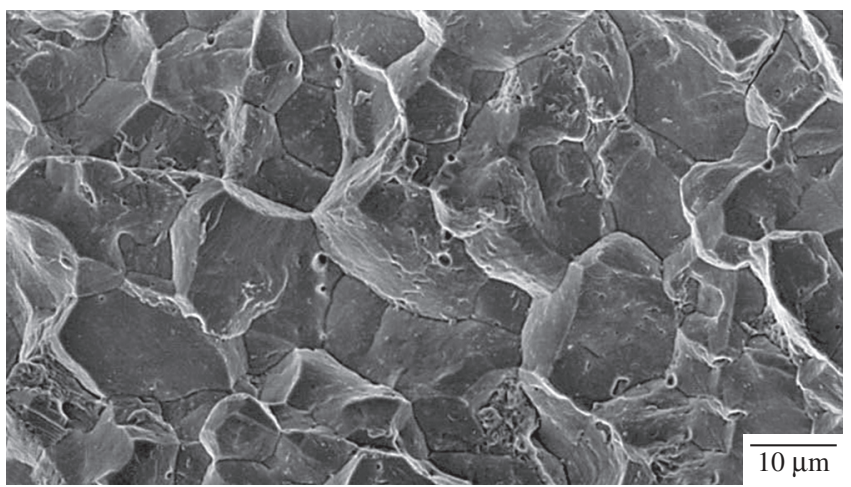

(d)

Figure 1. Fracture in case carburized microstructure in 4820 steel: a) overview of fatigue crack sequence; b) intergranular surface initiation; c) interface of transgranular and intergranular cracks; and d) overload intergranular fracture ${ }^{9}$. 
crack predominantly formed as a result of the separation of prior austenite grain boundaries at the component surface. However, higher endurance limits, above $1400 \mathrm{MPa}$, are associated with transgranular crack nucleation within the prior austenite grains ${ }^{11}$.

\subsection{Intergranular oxide control}

The atmosphere within a gas carburizing furnace typically contains a small amount of oxygen causing internal oxidation, typically to depths of 10 to $20 \mu \mathrm{m}$, particularly in the presence of susceptible alloying additions (e.g. Si, Mn, and $\mathrm{Cr}$ ). The oxides are frequently found along prior-austenite grain boundaries. Furthermore, oxidation removes solutes such as chromium and manganese that provide matrix hardenability ${ }^{12}$. This may result in the formation of non-martensitic microstructures such as ferrite, bainite, or pearlite upon quenching. The formation of the non-martensitic structures compromises both hardness and compressive residual stresses, thus reducing fatigue performance.

A recent study on the effects of high oxide-potential elements in a gas carburized SAE 4320-type steel has shown that control of alloy chemistry (e.g. Mn and Si levels) can virtually eliminate intergranular oxidation (IGO) and increase fatigue performance ${ }^{13}$. Figure 2 shows that a reduction in the level of oxidizing elements led to a lower IGO depth and correspondingly an increase in fatigue resistance in a series of alloys modified with Mo to maintain constant hardenabilty. In a related study, Cornelissen et al. showed that the IGO layer observed in Figure 2a for the high Mn, high Si steel could be eliminated by processing in a low pressure plasma-carburizing system (e.g. "vacuum carburizing"), and the endurance limit could be raised to $1525 \mathrm{MPa}^{14}$ This latter observation indicates that there are opportunities for alloy modifications that utilize elements undesirable in gas carburizing in steels designed for processing in vacuum carburizing systems ${ }^{8}$.

\subsection{Phosphorus and sulfur effects}

Control of phosphorus and sulfur to levels much lower than normally accepted for commercial steels (e.g. Table 1) has been shown to markedly improve the fatigue resistance of carburized steels. Sulfur as $\mathrm{MnS}$ particles improves machinability. However, the detrimental effects of $\mathrm{MnS}$ particles on fatigue performance were demonstrated, as shown in Figure 3a, by a study that systematically varied sulfur content in an SAE 8219-type steel ${ }^{1}$. The increase in bulk sulfur content from 0.006 to 0.029 weight percent resulted in a decrease in the endurance limit from 1260 to $1070 \mathrm{MPa}$.

Phosphorous strongly promotes quench embrittlement by its segregation to austenite grain boundaries and its apparent stabilizing effect on cementite ${ }^{7,10}$. A study on the effects of phosphorous content in a carburized SAE 4320 steel showed that high bulk phosphorous levels increase the phosphorous concentration at austenite grain boundaries and considerably lower bending fatigue endurance limits ${ }^{15}$. As shown in Figure $3 \mathrm{~b}$ when the bulk phosphorous content exceeded 0.017 weight percent, endurance limit dropped significantly, e.g. an increase in phosphorous from 0.017 to 0.031 weight percent reduced endurance limits from 1075 to $875 \mathrm{MPa}$. Despite the beneficial effects of low phosphorous levels on endurance limits, fatigue crack initiation was still intergranular in all direct-quenched alloys. This observation implies that there are opportunities for further control of intergranular fatigue crack nucleation by minimizing the effects of quench embrittlement through alloy additions, e.g. Si, in steels designed for vacuum carburizing 8 .

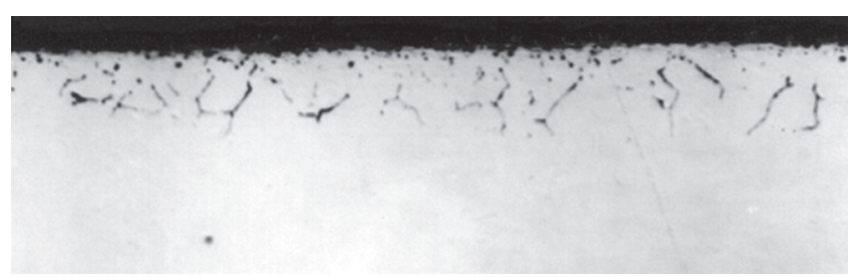

(a) $0.6 \mathrm{Mn}, 0.14 \mathrm{Si}, 0.17 \mathrm{Cr}, 0.26 \mathrm{Mo}$

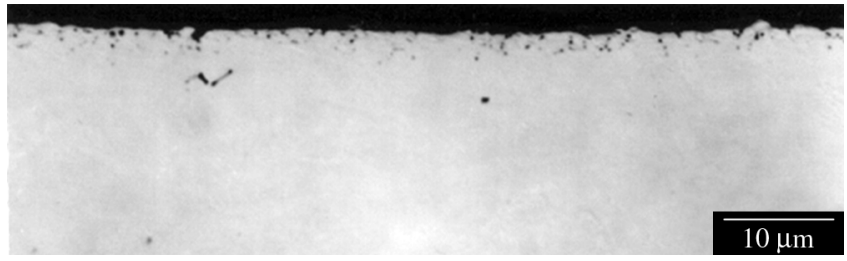

(b) $0.31 \mathrm{Mn}, 0.07 \mathrm{Si}, 0.18 \mathrm{Cr}, 0.47 \mathrm{Mo}$

Figure 2. Light optical micrographs (unetched) showing surface oxidation in gas carburized samples of modified 4320 steels (compositions, wt. (\%)): a) high $\mathrm{Mn}$, high Si, endurance limit $1075 \mathrm{MPa}$; and b) low $\mathrm{Mn}$, low Si, endurance limit $1350 \mathrm{MPa}^{13}$.

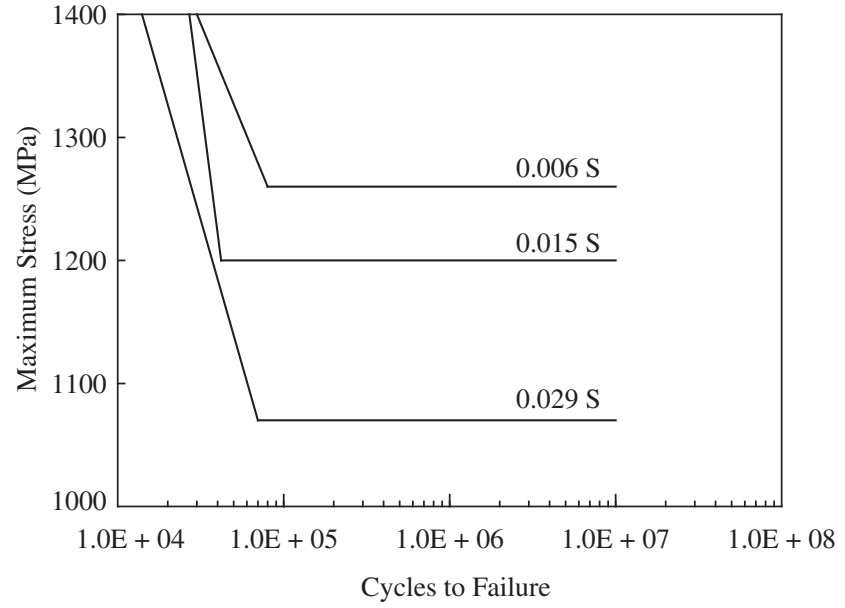

(a)

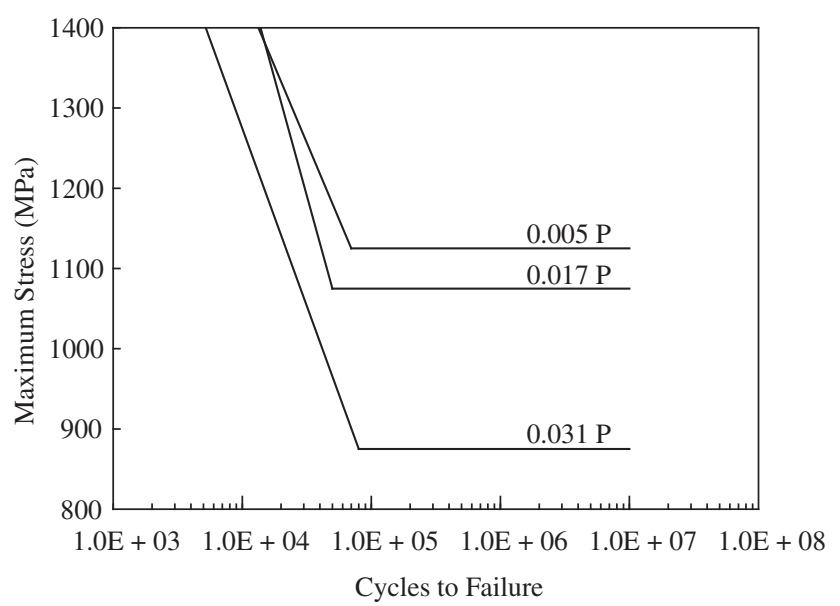

(b)

Figure 3. Effects of sulfur and phosphorus on the fatigue performance of a) SAE 8219 modified steel ${ }^{1}$; and b) SAE 4320 modified steel ${ }^{15}$. 


\subsection{Prior austenite grain size}

Control of prior austenite grain size in the case of carburized steels is extremely important in optimizing fatigue performance. With the expanded use of higher carburizing temperatures associated with vacuum carburizing, austenite grain size control will become even more important in the future. Fine grain sizes in carburized cases can be produced by reheating after the original quench cycle or by inducing multiple phase transformations. This approach has been successfully applied to increase the fatigue resistance of carburized SAE 4320 steel $^{2,4}$ and SAE 8620 steel $^{16}$. Hyde et al. in their analysis of single and triple reheats on the phosphorus-modified SAE 4320 steels shown in Figure $3 b$ found that the effects of phosphorus could be eliminated and the endurance limit, independent of phosphorous level, raised to approximately $1400 \mathrm{MPa}$ by grain refinement ${ }^{2}$.

Figure 4 summarizes results of the effects of different metallurgical variables, including austenite grain size, on the fatigue performance of carburized steels. Figure 4a compares correlation coefficients from a statistical analysis of a large set of experimental fatigue data ${ }^{17}$, all obtained in the same laboratory with the same specimen geometry, and shows that for these studies, the austenite grain size was the most important parameter that correlated to fatigue resistance. It was interpreted that with a refinement in austenite grain size decreased the susceptibility to intergranular fracture, in part due to the increased tortuosity of the intergranular crack path. In Figure $4 \mathrm{~b}$ the grain size effects are explored in more detail. Endurance limits are shown to follow a Hall-Petch relationship with grain size ${ }^{13}$.

The use of reheat treatments is not industrially attractive as a method to refine austenite grain size, as it requires additional processing steps. Several studies have shown that microalloy additions that form precipitates, primarily $\mathrm{Ti}$ and $\mathrm{Nb}^{18-20}$, and processing to control precipitate dispersions, can be used to suppress austenite grain growth during carburizing, particularly at the higher temperatures associated with vacuum carburizing. Example austenite grain structures obtained in a series of SAE 8620 steels with systematic $\mathrm{Nb}$ variations ${ }^{20}$ to a Ti-modified SAE 8620 steel $^{19}$ are presented in Figure 5. For samples annealed for 240 minutes at $1000{ }^{\circ} \mathrm{C}$, the prior austenite grain size decreased with an increase in $\mathrm{Nb}$ level. At this temperature, which is higher than normally used in gas carburizing, the highest $\mathrm{Nb}$ ad- dition was able to suppress abnormal grain growth. The significance of the different austenite grain structures shown in Figure 5 on the susceptibility to intergranular fracture remains undefined and should be the subject of future investigations.

\subsection{Residual stress and retained austenite in carburized steels}

Case retained austenite and residual stress levels are interrelated, and simultaneous control is required to optimize fatigue properties of carburized steels. Large amounts of retained austenite diminish compressive residual stresses and lower yield strengths, as illustrated by Medlin et al. ${ }^{4}$ who showed that the amount of retained austenite increased and surface residual stress decreased with an increase in case carbon content in gas carburized SAE 4320 steel. Correspondingly, the fatigue endurance limit increased with an increase in surface residual compressive stress.

Shot peening is also an effective way to modify the surface residual stress and surface retained austenite content. Shot peening was evaluated with the use of soft steel shot, hard steel shot, and a two-step (hard shot + low intensity-soft shot) peening treatment on a carburized SAE 4320 steel $^{5}$. All peening processes significantly reduced retained austenite at the specimen surface, from 28 volume percent in the as-carburized condition to less than 9 volume percent after all peening treatments. Surface hardness increased from 57 to $61 \mathrm{HRC}$, and compressive surface residual stresses dramatically increased from 100 to almost $1000 \mathrm{MPa}$. As a result, bending fatigue endurance limits increased from 1070 to over $1400 \mathrm{MPa}$ for all peening treatments evaluated.

\section{Deep Rolling}

Similar to shot peening, deep rolling is a process that utilizes cold working and non-uniform plastic strain to control surface hardness and residual stress to result in parts with improved fatigue resistance $^{21,22}$. Deep rolling also can be used to improve surface finish and radial profiles in fillets. Crankshafts, axle shafts, and fasteners have been the primary areas of interest for the application of deep rolling. In this paper, recent results ${ }^{21}$ are used to illustrate the importance of base material microstructure and properties on the subsequent response to surface modification by deep rolling.

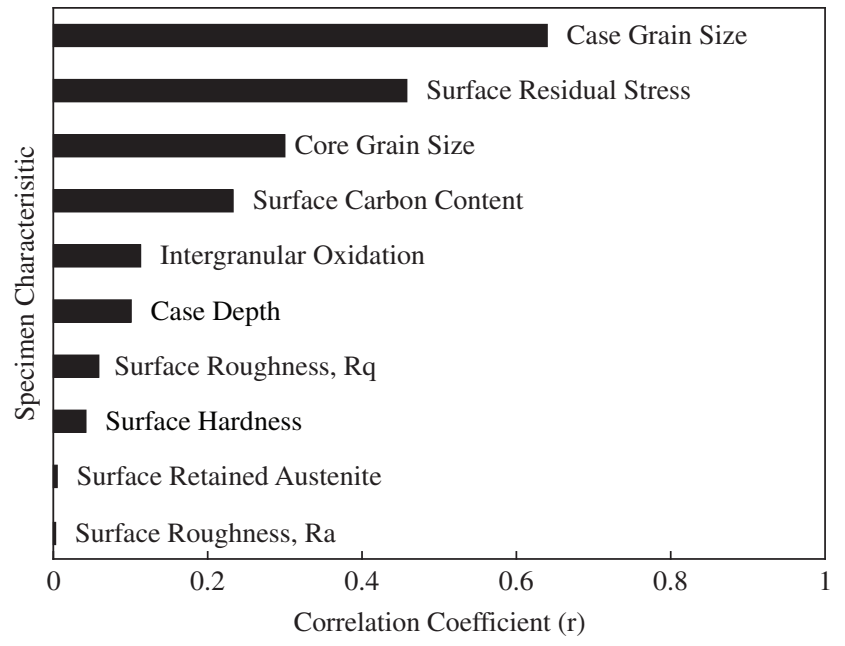

(a)

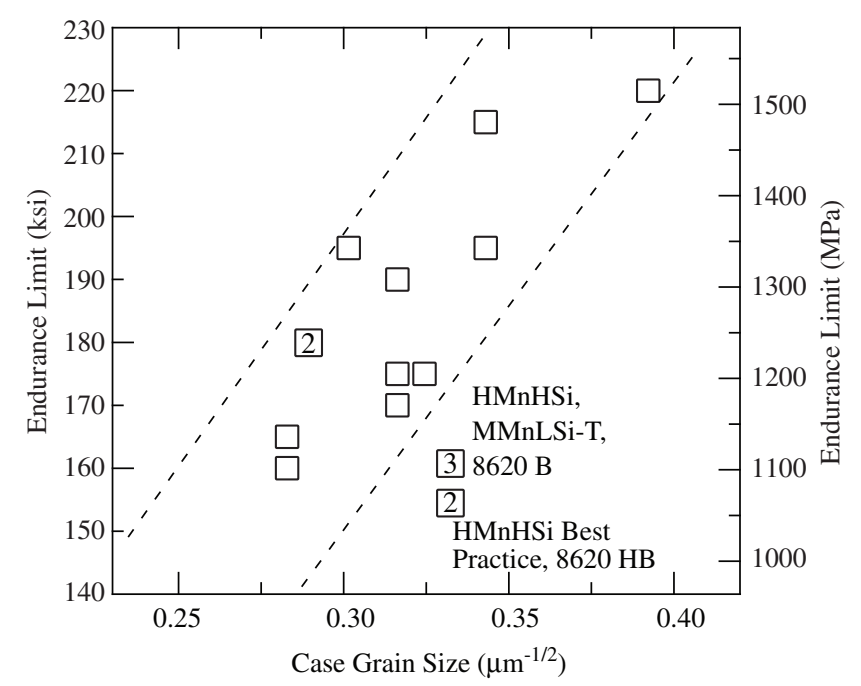

(b)

Figure 4. Assessment of the effects of metallurgical variables on the bending fatigue performance of carburized steels: a) statistical analysis of correlation coefficients bending fatigue ${ }^{17}$; and b) influence of grain size on bending fatigue in various steels ${ }^{13}$. 
Three medium carbon bar steels with microstructures characteristic of forging steels of interest for crankshaft and other automotive applications, were evaluated: a quenched and tempered steel with a heavily tempered martensitic microstructure (AISI 4140: $0.45 \mathrm{C}$,

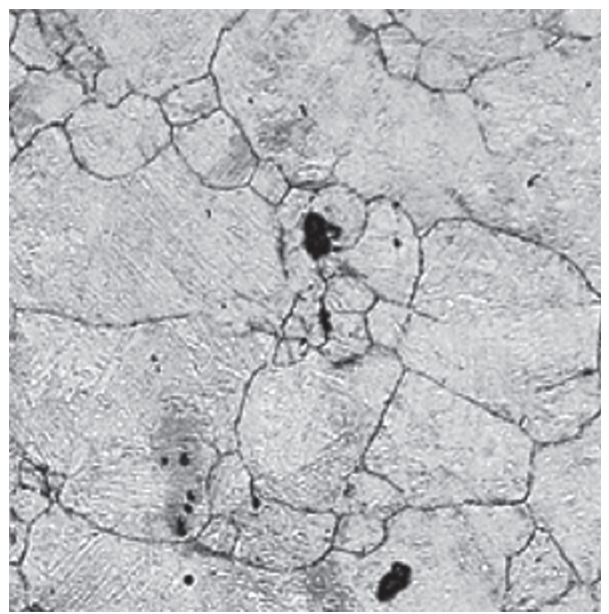

(a)

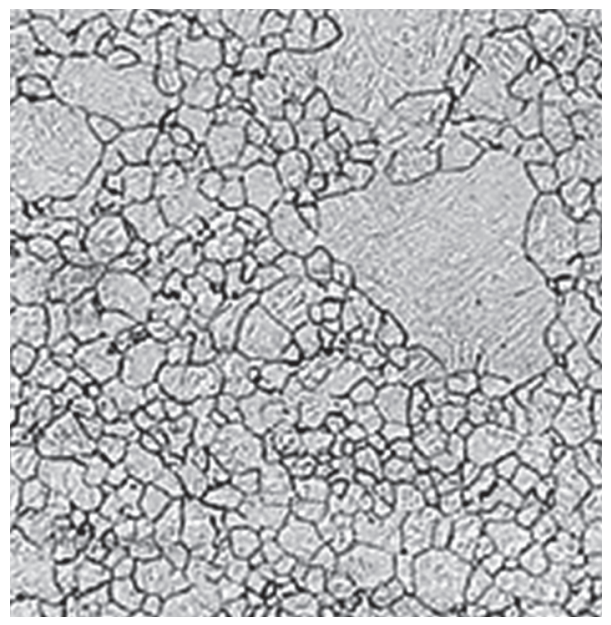

(b)

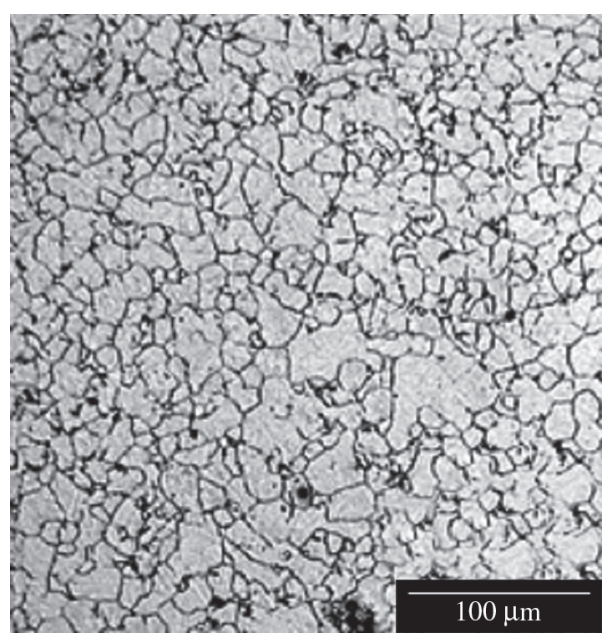

(c)

Figure 5. Light optical micrographs showing the effects of $\mathrm{Nb}$ additions on the prior austenite grain size formed in a Ti-modified steel annealed for $240 \mathrm{~min}$ at $1000{ }^{\circ} \mathrm{C}$, a) $0.02 \mathrm{Nb}$; b) $0.06 \mathrm{Nb}$; and c) $0.1 \mathrm{Nb}$, all compositions in wt. $(\%)^{20}$.
$0.85 \mathrm{Mn}, 0.85 \mathrm{Cr}, 0.22 \mathrm{Mo}$ - wt. (\%)); a non-traditional bainitic direct-cooled steel that contains 14.5 pct. retained austenite (NTB: $0.38 \mathrm{C}, 1.21 \mathrm{Mn}, 0.73 \mathrm{Si}, 0.22 \mathrm{Mo}, 0.099 \mathrm{~V}$ - wt. (\%)); and an as hot-rolled ferritic/pearlitic low alloy steel (C38M: $0.41 \mathrm{C}, 1.30 \mathrm{Mn}$, $0.56 \mathrm{Si}, 0.11 \mathrm{~V}-$ wt. $(\%)$ ). Differences in deformation behavior, primarily manifested as differences in the strain hardening behavior at low strains, are illustrated in the tensile and compressive true-stress versus true-strain curves shown in Figure 6a. The 4140 steel exhibits the highest yield stress, the appearance of discontinuous yielding, and the lowest strain hardening rate in the low strain region. In contrast, the other two steels exhibit lower yield stresses and higher strain hardening rates at low strains. As shown in Figure 6b, the response to deep rolling, plotted as cycles to failure versus rolling load in a study

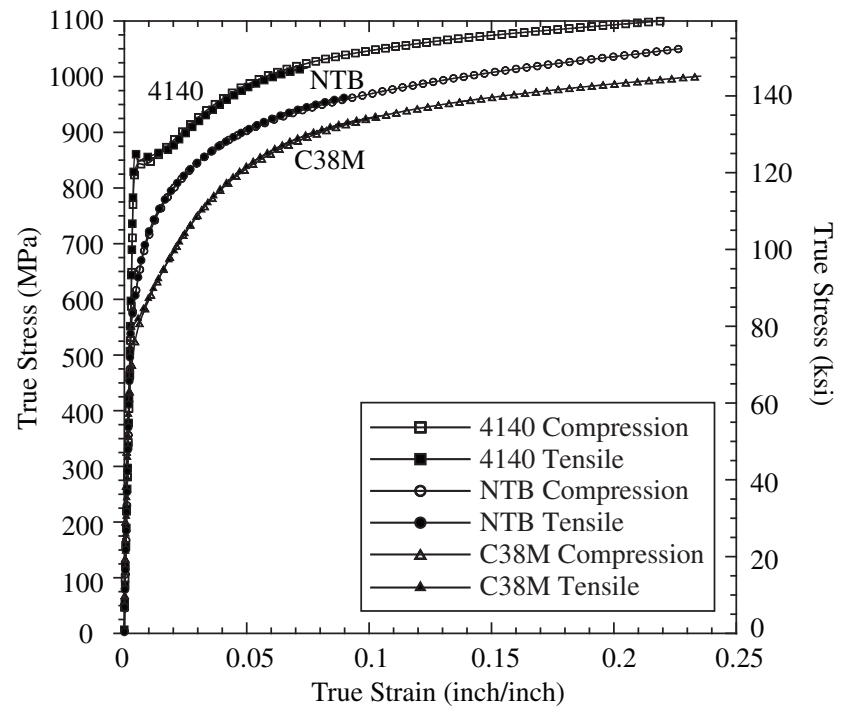

(a)

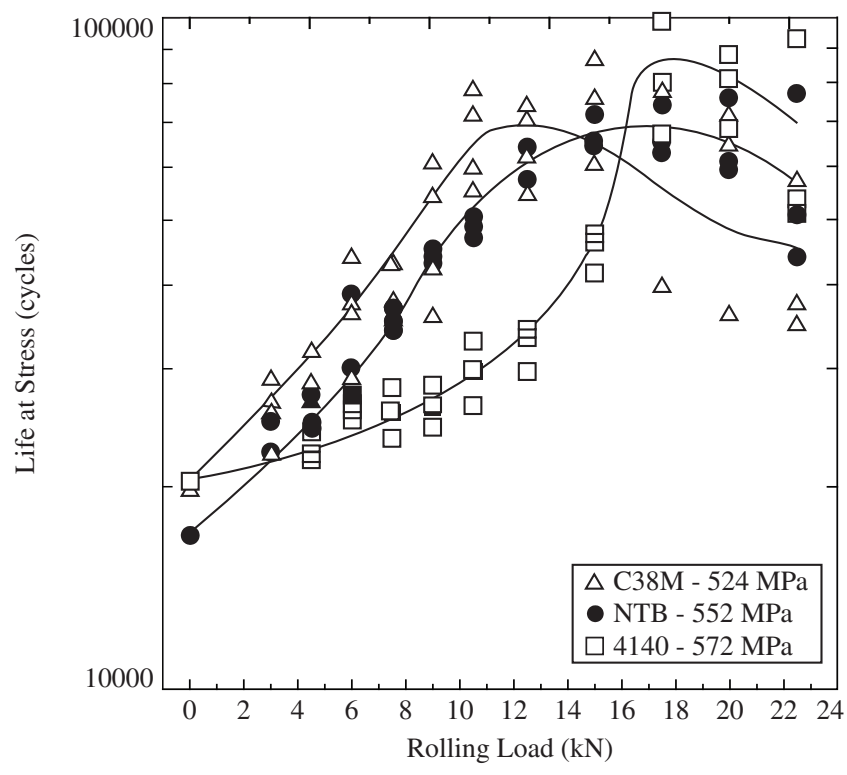

(b)

Figure 6. a) Summary of tensile and compressive true stress-strain curves; and b) deep rolling optimization curves for three automotive forging steels - imposed fatigue amplitudes are indicated in the figure legend ${ }^{21}$. 
designed to define the optimized deep rolling parameters for each steel, depends on the substrate deformation behavior. Specifically, the steels with higher strain hardening rates at low strains achieve a peak in performance at a lower imposed rolling load.

Complete reversed bending fatigue stress-life curves were obtained for each material in the as-received condition and processed at rolling conditions that correlated to the peak performance illustrated in Figure $6 \mathrm{~b}$. Figure 7a compares the fatigue data for the NTB steel and illustrates that deep rolling measurably improved the fatigue resistance. In Figure 7b, the degree of improvement in the fatigue behavior is summarized along with the base steel mechanical properties. While all three steels exhibit improvement in fatigue performance, as shown in Figure $6 \mathrm{~b}$ the two steels with microstructures that lead to rapid strain hardening exhibit a wider range in roller hardening loads associated with the peak processing condition, i.e. these steels are less sensitive to rolling process variables. Analysis of the fundamental relationships between deep rolling and the substrate deformation behavior is the subject of ongoing investigation ${ }^{23}$.

\section{Summary}

It is well known that the fatigue properties of automotive components depend on applied stresses, as dictated by design and operating conditions, as well as the surface finish, a product of the final manufacturing operations. Nonetheless, in this paper, several additional opportunities were presented to further optimize the fatigue behavior of surface-modified steels through alloying additions,

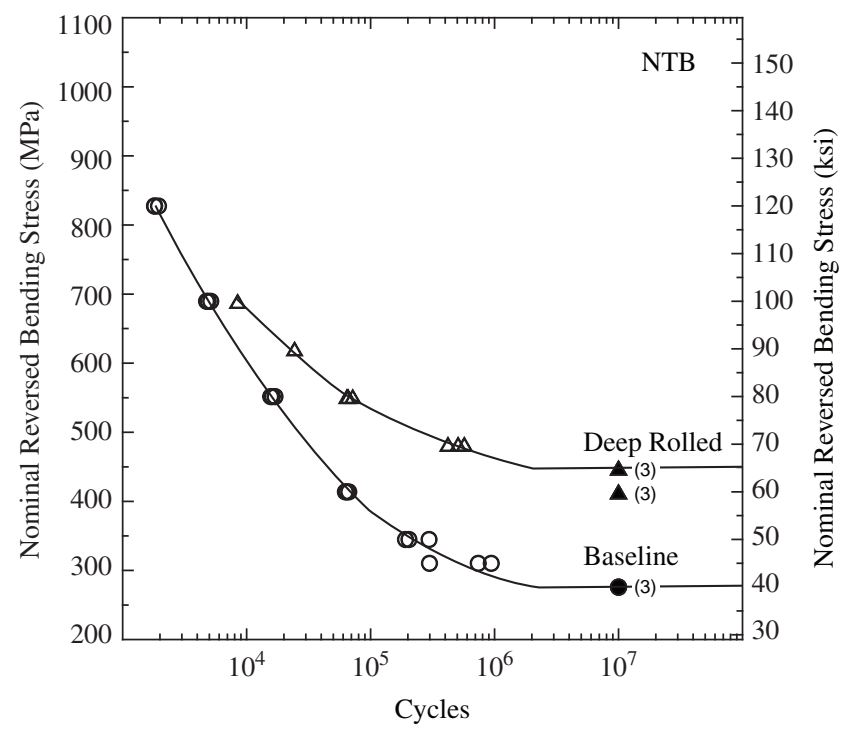

(a)

\begin{tabular}{cccc}
\hline Steel & $\begin{array}{c}\text { Yield Stress } \\
\text { MPa }\end{array}$ & $\begin{array}{c}\text { UTS } \\
\text { MPa }\end{array}$ & $\begin{array}{c}\text { Increase in } \\
\text { Endurance Limit }\end{array}$ \\
\hline 4140 & 848 & 946 & $51 \%$ \\
NTB & 479 & 881 & $62 \%$ \\
C38M & 552 & 835 & $60 \%$ \\
\hline
\end{tabular}

(b)

Figure 7. a) A comparison of deep rolled and baseline bending fatigue behavior for the NTB steel; and b) a summary of the extent of improvement imparted by the deep rolling process along with the base steel mechanical properties ${ }^{21}$. mechanical deformation, and microstructural control. It is anticipated that future automotive applications that demand even higher material performance will require simultaneous implementation of several of the material design philosophies illustrated here. The reader is encouraged to refer to many of the cited references for more detailed discussions of the highlighted studies.

\section{Acknowledgments}

The authors acknowledge the support of the Advanced Steel Processing and Products Research Center, an Industry-University Cooperative research center at the Colorado School of Mines. The authors also acknowledge the significant number of researchers, several of whom were not cited here, that have contributed to research programs reviewed here.

\section{References}

1. Erven K, Matlock D, Krauss, G. Effect of sulfur on bending fatigue of carburized steel. Journal of Heat Treating. 1991; 9(1):27-35.

2. Hyde R, Krauss G, and Matlock D. The effect of reheat treatments on fatigue and fracture of carburized steels. SAE Report No. 940788, SAE, Warrendale, PA; 1994.

3. Hyde R, Cohen R, Matlock D, Krauss G. Bending fatigue crack characterization and fracture toughness of gas carburized SAE 4320 steel. SAE Report $N^{o}$. 920534, SAE, Warrendale, PA; 1992.

4. Medlin D, Cornelissen B, Matlock D, Krauss G, Filar R. Effect of thermal treatments and carbon potential on bending fatigue performance of $\mathrm{SAE}$ 4320 gear steel. SAE Report $N^{o}$. 1999-01-0603, SAE, Warrendale, PA; 1999.

5. Sanders J. The effects of shot peening on the bending fatigue behavior of a carburized SAE 4320 steel. [Unpublished MS thesis]. Golden: Colorado School of Mines; 1993.

6. Wise J, Matlock D, Krauss G. Microstructure and fatigue resistance of carburized steels. In: Funatani K, Totten, G, editors. Proc. of the $20^{\text {th }}$ Heat Treating Conference; ASM International, Materials Park, OH. 2001; 2:1152-1161.

7. Hyde R, Matlock D, Krauss G. Quench embrittlement: intergranular fracture due to cementite and phosphorous in quenched carbon and alloy steels. Proc. of the $40^{\text {th }}$ Mech. Working and Steel Proc. Conference; ISS-AIME, Warrendale Pa. 1998; 921-928.

8. Spice J. Private communication, Colorado School of Mines, Golden, Co: 2004.

9. Krauss G, Matlock D, Reguly A. Microstructural elements and fracture of hardened high-carbon steels. Proc. of Thermec 2003. Trans Tech Publications, Inc., Uetikon-Zurich, Switzerland; 2003: 835-840.

10. Reguly A, Strohaecker T, Krauss G, Matlock D. Quench embrittlement of hardened 5160 as a function of austenitizing temperature. Metallurgical and Materials Transactions. 2004; 35A(1):153-162.

11. Pacheco J, Krauss G. Microstructure and high bending fatigue strength in carburized steel. Journal of Heat Treating. 1989; 7(2):77-86.

12. Dowling Jr. W, Donlon, Coppel W, Chernenkoff R, Darragh C. Bending fatigue behavior of carburized gear steels: four-point bend test development and evaluation. SAE Technical Report, $n^{\circ}$. 960977, SAE, Warrendale, PA, 1996.

13. Cornelissen B, Krauss G, Matlock D. Effects of alloying and processing on surface oxidation and bending fatigue of carburized steels. In: Mittemeijer E, Grosch J. Editors. Proceedings of the $5^{\text {th }}$ ASM Heat Treatment and Surface Engineering Conference in Europe. ASM International, Materials Park, Ohio; 2000:117-128.

14. Cornelissen B, Matlock D, Krauss G, Gondesen B, Hoffman F. Bending fatigue performance of gas- and plasma-carburized steels. SAE Technical Publication, $n^{o}$.1999-01-0602, SAE, Warrendale, PA, 1999.

15. Hyde R, Krauss G, Matlock D. Phosphorus and carbon segregation: effects on fatigue and fracture of carburized 4320 steel. Metallurgical Transactions A. 1994; 25A(6):1229-1240. 
16. Spice J, Matlock D, Fett G. Optimized carburized steel fatigue perform ance as assessed with gear and modified brugger fatigue tests. SAE Technical Publication, $n^{\circ}$. 2002-01-1003, SAE, Warrendale, PA; 2002.

17. Wise J, Matlock D. Bending fatigue of carburized steels: a statistical analysis of process and microstructural parameters. SAE Technical Publication, $n^{o}$. 2000-01-0611, SAE, Warrendale, PA; 2000.

18. Bleck W. et al. Development of carburising steels for ultra high process temperatures. European Commission Report, no. EUR 20630; 2003.

19. Davidson S, Wise J, Speer J. The influence of titanium on grain size in high-temperature carburized steels. Proc. of the $20^{\text {th }}$ ASM Heat Treating Conference, St. Louis, MO. ASM International, Materials Park, Ohio; 2000:1144-1151
20. Alogab K. Austenite grain-size control at elevated temperature in microalloyed carburizing steels. [Unpublished $\mathrm{PhD}$ thesis]. Golden: Colorado School of Mines; 2004.

21. Richards M, Matlock D, Speer J. Deep rolling response of notched medium carbon bar steels. SAE Technical Publication, no. 2004-01-1528. SAE, Warrendale, PA, 2004.

22. Kloos K, Adelmann J, Effect of deep rolling on fatigue properties of cast irons. Journal of the Mechanical Behavior of Materials (UK). 1989; 2(12):75-86.

23. Richards M. Private communication. Colorado School of Mines, 2004. 